\title{
PLANTAR PRESSURES IN HEALTHY CHILDREN AND IN CHILDREN WITH MYELOMENINGOCELE
}

\author{
Malcolm C. Hay, Perth, Australia, and \\ Geoffrey Walker, Carshalton, Surrey, England \\ From Queen Mary's Hospital for Children, Carshalton
}

Pressure sores and trophic ulceration in the feet of children with neurological defects resulting from myelomeningocele and spina bifida are becoming an increasing problem as more children born with this severe anomaly now survive. This research was designed to confirm a simple idea that whereas the surface area of specialised weight-bearing plantar skin

TABLE I

The Harpenden Study: Plantar Pressures in Twenty-five Boys

\begin{tabular}{|c|c|c|c|c|}
\hline \multirow[b]{2}{*}{ Number } & \multicolumn{2}{|c|}{ Minimum } & \multicolumn{2}{|c|}{ Maximum } \\
\hline & $\begin{array}{c}\text { Age } \\
\text { (years) }\end{array}$ & $\begin{array}{c}\text { Pressure } \\
(\mathrm{g} / \mathrm{sq} \mathrm{mm})\end{array}$ & $\begin{array}{c}\text { Age } \\
\text { (years) }\end{array}$ & $\begin{array}{c}\text { Pressure } \\
(\mathrm{g} / \mathrm{sq} \mathrm{mm})\end{array}$ \\
\hline $\begin{array}{r}1 \\
2 \\
3 \\
4 \\
5 \\
6 \\
7 \\
8 \\
9 \\
10 \\
11 \\
12 \\
13 \\
14 \\
15 \\
16 \\
17 \\
18 \\
19 \\
20 \\
21 \\
22 \\
23 \\
24 \\
25\end{array}$ & $\begin{array}{l}6 \\
6 \\
1 \cdot 5 \\
5 \\
7 \\
6 \cdot 5 \\
5 \\
3 \\
6 \\
6 \\
5 \cdot 5 \\
5 \cdot 5 \\
6 \\
5 \cdot 5 \\
5 \\
2 \\
4 \\
3 \\
4 \\
4 \\
3 \\
5 \\
5 \\
3 \\
4\end{array}$ & $\begin{array}{l}3.15 \\
3.68 \\
3.36 \\
3.99 \\
5 \\
3.90 \\
5.19 \\
3.54 \\
3.95 \\
3.92 \\
3.08 \\
3.90 \\
3.50 \\
4.10 \\
4.04 \\
3.83 \\
4.11 \\
3.42 \\
3.92 \\
3.77 \\
3.11 \\
4.08 \\
3.36 \\
3.55 \\
3.24\end{array}$ & $\begin{array}{l}20 \\
20 \\
18 \\
17 \\
18 \\
20 \\
19 \\
18 \\
16 \\
17 \\
15 \\
18 \\
20 \\
20 \\
16 \\
19 \\
18 \\
15 \\
16 \\
18 \\
17 \\
18 \\
17 \\
15 \cdot 5 \\
18\end{array}$ & $\begin{array}{l}5.35 \\
5.03 \\
4.67 \\
5.45 \\
5.82 \\
4.47 \\
5.86 \\
7.63 \\
4.59 \\
5.34 \\
3.83 \\
4.46 \\
5.64 \\
5.74 \\
5.45 \\
5.67 \\
4.37 \\
5.04 \\
5.66 \\
4.43 \\
4.42 \\
5.29 \\
4.69 \\
4.17 \\
4.87\end{array}$ \\
\hline Average & 4.8 & $3 \cdot 79$ & $17 \cdot 72$ & $5 \cdot 12$ \\
\hline
\end{tabular}

Mean pressure increase 35 per cent

$x-y$

Mean 1.361

Sum squares $\cdot 675$

S.D. $\cdot 822$

$(\mathrm{t}=8 \cdot 11)$

$(\mathrm{p}<0.001)$

increased during growth "by the square", the body weight increased "by the cube", with a resulting substantial increase in perpendicular static plantar pressure. Although it has not been possible to establish such a simple and attractive arithmetical relationship, we have been able to show a definite increase in the plantar pressures of normal children during growth. In addition the plantar pressures of a group of children with spina bifida have been found to be above the average level for the feet of healthy children of similar ages. 


\section{METHOD AND MATERIAL}

Through the kindness of Professor J. M. Tanner and Mr R. H. Whitehouse of the Institute of Child Health, London, and of Dr C. Asher, late of the Department of Education and Science, we were allowed access to footprints and weight records of twenty-five boys and twenty-five girls, recorded from the age of about five years to maturity. This work on healthy children was originally done as part of the Harpenden Growth Study (Tanner 1962). The footprints were recorded by a pedograph with the whole weight passing through the foot. The surface

TABLE II

The Harpenden Study: Plantar Pressures in Twenty-five Girls

\begin{tabular}{|c|c|c|c|c|}
\hline \multirow[b]{2}{*}{ Number } & \multicolumn{2}{|c|}{ Minimum } & \multicolumn{2}{|c|}{ Maximum } \\
\hline & $\underset{\text { (years) }}{\text { Age }}$ & $\begin{array}{c}\text { Pressure } \\
(\mathrm{g} / \mathrm{sq} \mathrm{mm})\end{array}$ & $\begin{array}{c}\text { Age } \\
\text { (years) }\end{array}$ & $\begin{array}{c}\text { Pressure } \\
(\mathrm{g} / \mathrm{sq} \mathrm{mm})\end{array}$ \\
\hline $\begin{array}{r}1 \\
2 \\
3 \\
4 \\
5 \\
6 \\
7 \\
8 \\
9 \\
10 \\
11 \\
12 \\
13 \\
14 \\
15 \\
16 \\
17 \\
18 \\
19 \\
20 \\
21 \\
22 \\
23 \\
24 \\
25\end{array}$ & $\begin{array}{l}7 \\
5 \cdot 5 \\
3 \cdot 5 \\
5 \cdot 5 \\
7 \cdot 5 \\
5 \cdot 5 \\
4 \\
2 \cdot 5 \\
5 \\
5 \cdot 5 \\
5 \\
4 \cdot 5 \\
5 \\
5 \cdot 5 \\
6 \\
5 \cdot 5 \\
5 \\
4 \\
6 \\
5 \cdot 5 \\
7 \\
7 \\
7 \\
7 \cdot 5 \\
7 \cdot 5\end{array}$ & $\begin{array}{l}3.58 \\
4 \cdot 27 \\
3.32 \\
4.06 \\
4.27 \\
4.24 \\
5.07 \\
4.04 \\
5.56 \\
4.09 \\
4.47 \\
4.66 \\
4 \cdot 17 \\
3.23 \\
4.71 \\
3.60 \\
3.43 \\
4.04 \\
4.73 \\
4.62 \\
3.92 \\
3.97 \\
4.61 \\
6.05 \\
4.72\end{array}$ & $\begin{array}{l}19 \\
20 \\
17 \\
20 \\
20 \\
18 \\
17 \\
16 \\
20 \\
18 \\
15 \\
19 \\
14 \\
13 \\
18 \\
16 \\
16 \\
19 \\
17 \\
16 \\
17 \\
18 \\
15 \\
17 \\
19\end{array}$ & 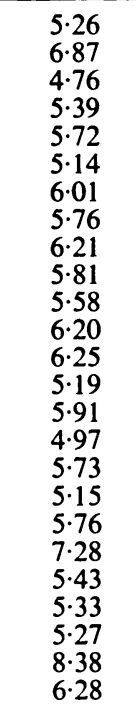 \\
\hline Average & $5 \cdot 44$ & $4 \cdot 30$ & $17 \cdot 36$ & $5 \cdot 83$ \\
\hline
\end{tabular}

Mean pressure increase 35.58 per cent $x-y$

Mean 1.487

Sum squares $\cdot 29988$

S.D. $\cdot 5476$

$(\mathrm{t}=13 \cdot 3)$

$(\mathrm{p}<0.001)$

area on the pedograph was then measured with a Mott planimeter. As very few of the Harpenden children were measured before the age of five years, similar measurements were made on a random selection of thirty-one girls and twenty-six boys with neither orthopaedic nor neurological problems, aged from two to five years, in the general wards of Queen Mary's Hospital for Children. In addition, identical measurements were made of the body weight and feet of twenty male and nineteen female children with spina bifida (seventy-eight feet, all with neurological defects).

From these measurements it was possible to calculate perpendicular static plantar pressure, and this was expressed as grammes per square millimetre.

VOL. 55 B, NO. 4, NOVEMBER 1973 


\section{RESULTS}

The results are presented in three sections, as follows.

The Harpenden children-Plantar pressures of all the Harpenden children (twenty-five boys and twenty-five girls) were calculated at about five years and at maturity, and a statistically significant increase of 35 per cent in the mean pressure between these ages was revealed (Tables I and II).

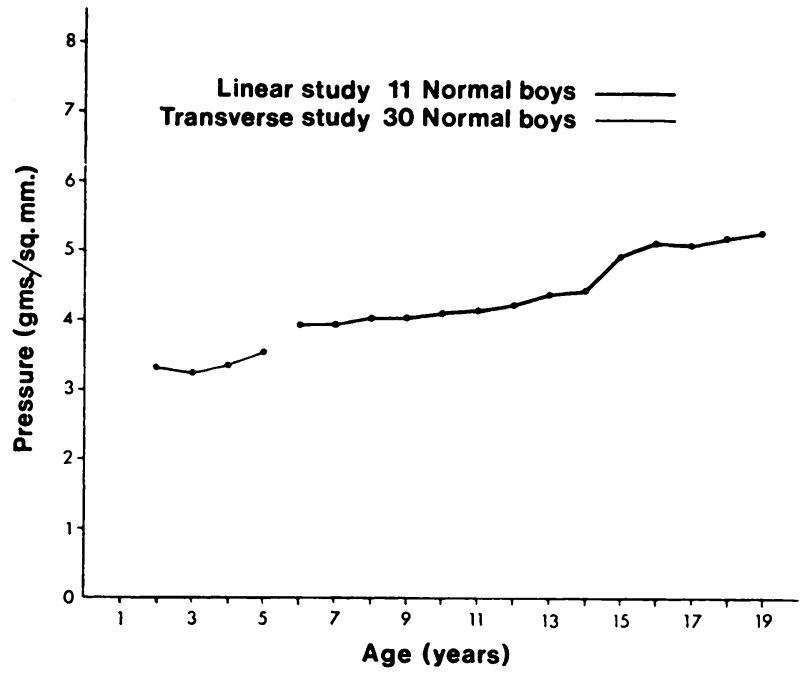

Fig. 1

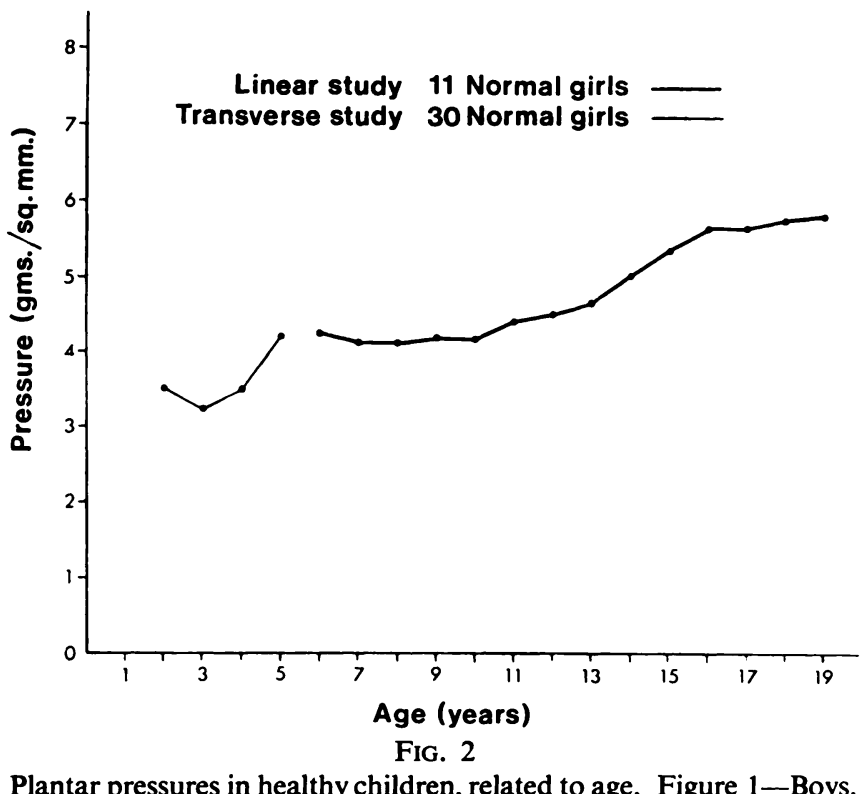

Figure 2-Girls.

In twenty-two of these children (eleven boys and eleven girls) the measurements were studied in greater detail, plantar pressures being calculated at yearly intervals. The results of this longitudinal study are recorded graphically in composite form for each sex, and there is an obvious increase in pressure with age (Figs. 1 and 2).

Random selection of healthy children-Plantar pressures of a random selection of healthy children between two and five years of age (thirty-one girls and twenty-six boys) were plotted 
on the composite graphs of the Harpenden children (Figs. 1 and 2). Although in no way was continuity with the Harpenden linear records inferred, the result suggests that plantar pressure rises between the ages of two and five years.

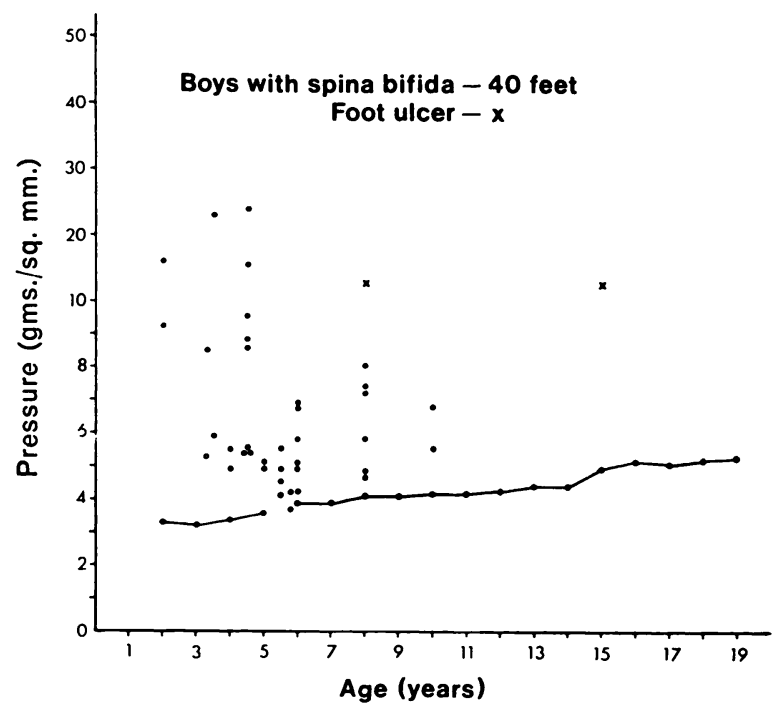

Fig. 3

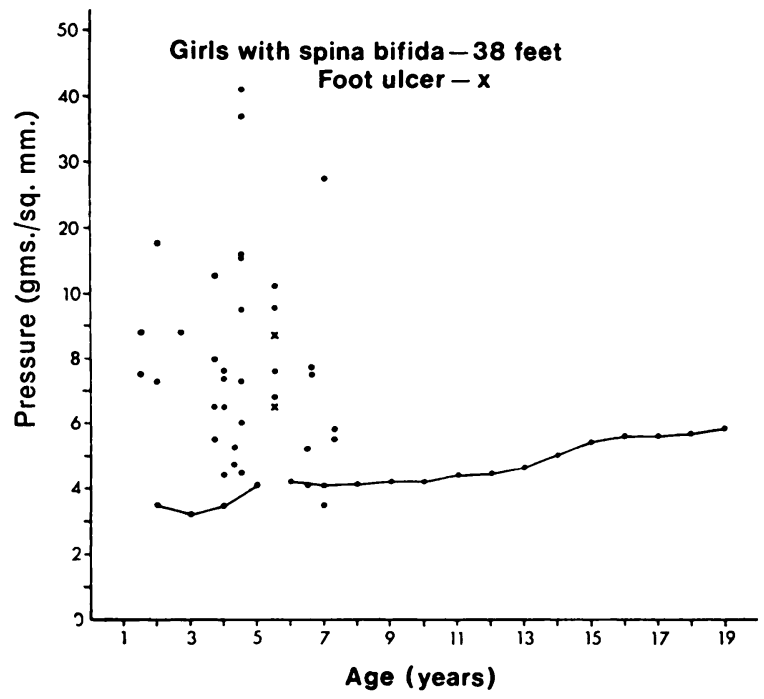

Fig. 4

Plantar pressures in children with spina bifida, related to age. Figure 3-Boys. Figure 4-Girls.

Children with spina bifida-Plantar pressures of seventy-eight feet of children with spina bifida (twenty boys and nineteen girls) are recorded graphically (Figs. 3 and 4). It is evident that pressures are greater in the feet of the children with spina bifida than in those of the healthy children. Further analysis of the measurements reveals that the area of pressure in the sole on weight-bearing is on average less in children with spina bifida than in healthy children. This is mainly due to the smaller size of the feet of the children with spina bifida.

VOL. 55 B, NO. 4, NOVEMBER 1973 


\section{DISCUSSION}

We have shown an increase in plantar pressures throughout growth in healthy children, and a raised plantar pressure in children with spina bifida, certainly up to about ten years of age. It seems likely that as children with spina bifida grow older their abnormally high plantar pressures will continue to increase, particularly as so many of them put on excess weight. This increase in plantar pressure is therefore one factor to be considered in the production of pressure sores and trophic ulceration. It is often associated with fixed deformity, which was so well shown by Clawson and Seddon (1960) to be important in plantar ulceration after sciatic nerve injury. Static foot pressure is only one of the forces acting on the sole of the foot, the others being thrust and penetration in the perpendicular component of pressure, and sliding friction and shear factors related to the parallel component. These were well described by Bauman, Girling and Brand (1963), dealing with plantar pressures and trophic ulceration in leprosy. In this respect it is of interest that in the experience of one of us (G. W.) in Africa, leprosy very rarely produces anaesthesia and fixed deformity in young children's feet (Smith 1972).

Kosiak (1959) and Lindan (1961) showed by experiments on animals that a pressure as low as 0.8 gramme per square millimetre would render skin ischaemic, and if maintained long enough would cause necrosis and ulceration, while only 2 grammes per square millimetre would overcome total systolic blood pressure. Both these pressures are exceeded in the feet of healthy children and of those with spina bifida, and one can only surmise that continual movement, certainly in feet without neurological defect, plays a very important part in preventing the plantar ischaemia and ulceration which otherwise would occur. How this is prevented in the paralysed feet associated with spina bifida remains to be explained, although many of the older severely paralysed children opt for a wheel-chair existence. In this case ischial and sacral sores are going to be a greater problem than plantar ulceration, particularly with the obesity so commonly found in immobile adolescents.

Although fixed deformity in a foot is an important factor in producing areas of exceptionally high pressure, a "flail deformity" can also be associated with areas of increased pressure. In cases of spina bifida the situation is arising, and being produced by operation, in which although there is neither active muscle action below the knee nor fixed deformity, the child stands on his heel with the forefoot lying limply on the ground and bearing only a minimal share of the load. This is particularly seen in flail feet in which an excision type of posterior release done some years previously for equinus deformity has produced satisfactory return of passive ankle and foot movements (Walker 1971). It is possible that in these feet part of the weight-bearing load can be transmitted to the forefoot by the use of suitable boots and calipers, but as yet we have no specific evidence that this is so. Some of these feet will require midtarsal or ankle fusions to spread the load, but great care will have to be exercised to avoid producing fixed deformity.

\section{SUMMARY}

1. It has been shown in fifty normal feet that the perpendicular static plantar pressures rise by about 35 per cent between the ages of five years and maturity.

2. It is very likely that similar increases in plantar pressures occur between two and five years of age.

3. The plantar pressures in seventy-eight feet of children with spina bifida were with a few exceptions substantially higher than those of normal children of the same age. It is likely that this is so, at least in part, because the feet of children with spina bifida are smaller than normal.

4. This increase in perpendicular static pressure during growth must be relevant in the production of trophic foot ulceration.

5. The existence and importance of "flail deformity" as a factor producing areas of increased pressure and ulceration in anaesthetic feet is postulated. 
We wish to record our gratitude to Professor J. M. Tanner and Mr R. H. Whitehouse of the Institute of Child Health, London, and to Dr C. Asher, late of the Department of Education and Science, for access to the Harpenden Growth Study footprint records and for the use of the facilities of the Institute.

An early report of this work was presented to a meeting of the Section of Orthopaedics of the Royal Society of Medicine in 1971.

\section{REFERENCES}

Bauman, J. H., Girling, J. P., and Brand, P. W. (1963): Plantar Pressures and Trophic Ulceration. Journal of Bone and Joint Surgery, 45-B, 652.

Clawson, D. K., and Seddon, H. J. (1960): The Late Consequences of Sciatic Nerve Injury. Journal of Bone and Joint Surgery, 42-B, 213.

KosiaK, M. (1959): Etiology and Pathology of Ischemic Ulcers. Archives of Physical Medicine and Rehabilitation, 40, 62.

Lindan, O. (1961): Etiology of Decubitus Ulcers: An Experimental Study. Archives of Physical Medicine and Rehabilitation, 42, 774.

SMITH, V. (1972): Personal communication.

TANNer, J. M. (1962): Growth at Adolescence. Second edition. Oxford: Blackwell Scientific Publications.

Walker, G. (1971): The Early Management of Varus Feet in Myelomeningocele. Journal of Bone and Joint Surgery 53-B. 462. 